\title{
Pure Endoscopic Endonasal Surgery for Pituitary Adenomas: Technique and Early Results in Banha Neurosurgery Department
}

\author{
MOHAMMED H. EL-TANTAWY, M.D.*; AHMED A. ARAB, M.D.* and MOHAMED G. HAMED, M.D.** \\ The Department of Neurosurgery, Faculties of Medicine, Benha* and E.N.T., Helwan** Universities
}

\begin{abstract}
Background: Surgery for pituitary adenomas passed though several stages of refinement during the past decades. During the past 20 years a major shift has been made by neurosurgeons towards endoscopic pituitary surgery. This has been aided by the great development in technologies of rod lens and high resolution video cameras. The panoramic view offered by the endoscope made the surgery more safe and radical in removing the tumor. Now it is widely accepted in most neurosurgical institutes that the endoscopic endonasal surgery should be the gold standard in pituitary surgery.
\end{abstract}

Aim of Study: In this study we report our early results, challenges we faced and the problems we solved in applying the technique of pure endoscopic endonasal surgery for pituitary adenomas in Banha Neurosurgery Department.

Study Design: This is a retrospective study case series of 35 patients with pituitary adenomas. All patients were treated surgically using the pure endoscopic endonasal technique. Patients had been followed after surgery for a period of time ranged from 4 to 36 months during the years from February 2012 to March 2015.

Patients and Methods: Thirty five patients were included; twenty with nonfunctioning pituitary adenomas, (nine with suprasellar extension only and 11 with parasellar extension) and fifteen with functioning adenomas including $3 \mathrm{ACTH}$ secreting, $8 \mathrm{GH}$ secreting and 4 prolactinomas. Patients were endocrinologically, ophthalmologically and radiologically evaluated using CT paranasal sinus and MRI pituitary scans. Pre and post-operative scans as well as levels of pituitary hormones have been compared and evaluated for the degree of tumor resection, visual improvement and endocrinological cure.

Results: Gross total resection of the tumor has been achieved in 23 patients $(65.7 \%)$ while 12 patients $(34.3 \%)$ had incomplete resection. Among 15 patients with pre operative visual deficits, 13 patients $(86,6 \%)$ showed variable degrees of visual improvement and 2 only (13.3\%) did not improve. Endocrinological cure was $75 \%$ in $\mathrm{GH}$ secreting adenomas, $75 \%$ in prolactinomas and $66.7 \%$ in ACTH secreting adenomas.

Correspondence to: Dr. Ahmed A. Arab, E-Mail: arabneuro@gmail.com ahmed.arab@ffmed.bu.edu.eg
The most common complications were transient post-operative DI and inrtaoperative CSF laek. No reported deaths, major vascular injury or worsening of vision.

Conclusion: The pure endoscopic endonasal technique, although challenging, it is less traumatic, and associated with good outcome.

Key Words: Endoscopic-Endonasal - Pituitary-Adenomas.

\section{Introduction}

ENDOSCOPIC endonasal surgery for pituitary tumors has been refined since its introduction. The popularity of using the endoscope in pituitary surgery started in early $90 \mathrm{~s}$. The panoramic views offered by the endoscope allowed neurosurgeon for better resection of the tumor with less morbidity to the patient [1].

In the past few years, because of the familiarity of the endoscope by neurosurgeons, the technique of pure endoscopic endonasal surgery has become superior to the use of microscope in pituitary surgery [2].

In this study, we reported our results and outcome for pituitary patients undergoing this technique in our department of neurosurgery at Banha University Hospital.

\footnotetext{
Abbreviation:

ACTH : Adreno CorticoTropic Hormone.

GR : Growth Hormone.

IGF1 : Insulin-like Growth Factor 1.

GTR : Growth Total Removal.

MRI : Magnetic Resonance Imaging.

CT : Computerized Tomography.

CSF : Cerebro Spinal Fluid.

BID : Bis in Die (twice daily).

ENT : Ear Nose and Throat.

TSH : Thyroid Stimulating Hormone.

T3 : Triiodothyronine.

T4 : Thyroxine Hormone.
} 


\section{Patients and Methods}

Between February 2012 and March 2015, thirt five patients with pituitary tumors had surgery using the pure endoscopic endonasal technique in the Department of neurosurgery at Banha University Hospitals.

\section{Pre-operative assessment:}

All patients have been subjected to detailed history taking, endocrinological, neuroophthalmological, and radiological assessment. Endocrinological assessment included: Plasma levels of cortisol, ACTH, T3, T4, TSH, prolactin, GH, testosterone, and estradiol. In patients suspected to have GH secretory adenomas IGF1 also was done. Neuroophthalmological assessment included visual field and visual acuity testing. All patients underwent CT paranasal sinuses, and MRI pituitary scan to record full detailed anatomy of nasal cavity and condition of sphenoidal and ethmoidal sinuses as well as position and extension of pituitary adenoma and gland. Other lab oratory and cardiological assessment has been done for all patients to ensure their fitness for anesthesia.

\section{Surgical technique:}

In all patients we used the pure endoscopic endonasal technique. Using 0 and 30 degree angle sinuscopes $18 \mathrm{~cm}$ length and $4 \mathrm{~mm}$ diameter. Binostril 4 hand technique has been adopted with the ENT surgeon starting the procedure, then during the sellar phase of the procedure the neurosurgeon join the team and with his two hands dissecting and removing the tumor, suction in one hand and curette in the other hand, while the scope is hold by the ENT surgeon rostral in the field Fig. (1).

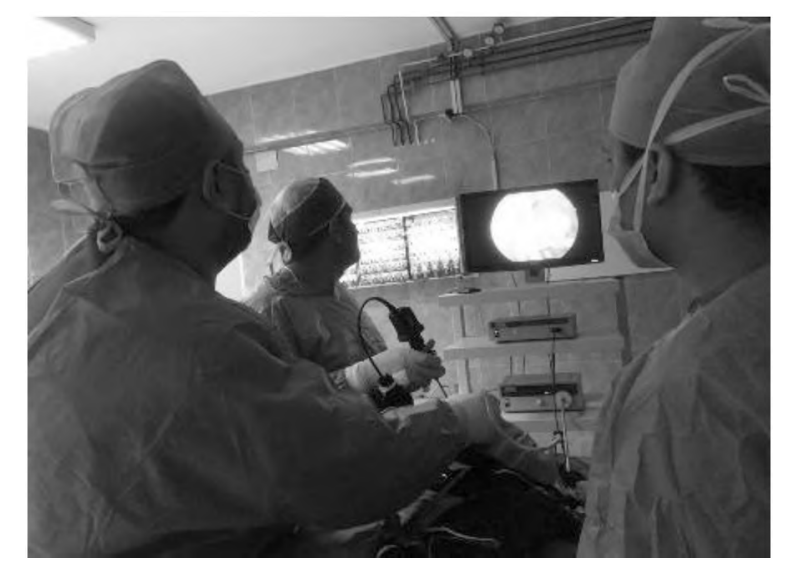

Fig. (1): Binostril 4 hand technique with the ENT surgeon holding the scope rostral in the field and the neurosurgeon working with his 2 hands from both nostrils with suction and curette.

Positioning of the patient is a very important step, which will help in bringing the sella directly in front of the scope. Patient is placed supine with his upper half of body elevated 30 degrees, chinforehead line is parallel to the floor, with the head tilted towards the surgeon 15 degrees. Flexion of the head more gives an access to the clivus while extension of the head will put us on anterior cranial fossa floor.

The technique passes through three phases, the 1 st phase is usually done by the ENT surgeon alone is the nasal phase. Both nostril are packed with saline adrenaline as a local vasoconstrictor. Although we usually start surgery from the right nostril, both nostrils should be explored at the beginning to determine if there is any anatomical consideration as septal deviation or chonca bullosa that may obstruct the corridor to the sphenoid and necessitate correction first.

In most cases it is possible to work around septal deviation, however, in severe septal deviation a septoplasty is initially performed. Navigating the scope parallel to the nasal floor at the beginning to reach the nasopharynx will make us more oriented with the nasal anatomy, then elevating the scope up to identify the middle turbinate and push it laterally to widen the corridor Fig. (2A). Next is trying to locate the sphenoidal ostia which is usually found just medial to the superior turbinate in the upper part of the spheno-ethmoidal recess. In some cases finding the ostia is difficult because of mucosal hypertrophy specially in acromegalic patients and in this situation we should depend mainly on the anatomic landmarks provided by the preoperative imaging. In some cases a pediculated septal flap is harvested and tucked away in the nasopharynx to be used in construction of sellar floor in case of CSF leak. Usually we can open the anterior sphenoidal wall by drilling $1.5 \mathrm{~cm}$ above and medial to the lower border of middle turbinate.

The $2 \mathrm{nd}$ phase is the sphenoidal phase in which we enlarge the anterior sphenoidotomy to explore the anatomical landmarks inside the sphenoid cavity. This can be done by removing the vomur and posterosuperior part of the nasal septum Fig. (2B), at this step we can start the Binostril bimanual technique which will significantly increases the range of motion of the instruments which will make it more efficient and safe in accessing the tumor and control the bleeding. The anterior sphenoid wall should be drilled from superior turbinate in one side to the other, and from the ostia above to the clivus below, the intersphenoidal septae should be identified in the pre-operative CT scan and removed until flush with the sella then the 
mucosa of the sphenoid should be removed only over the sellar floor.

At the end of the sphenoidal phase, we should identify all the anatomical landmarks inside the cavity, these landmarks will help in further dissection; they are the paraclival and parasellar carotid prominence, sellar bulge, opticocarotid recess in both sides, planum above and clival recess below. Presence or absence of these landmarks depends mainly on the degree of pneumatization of the sphenoid sinus.
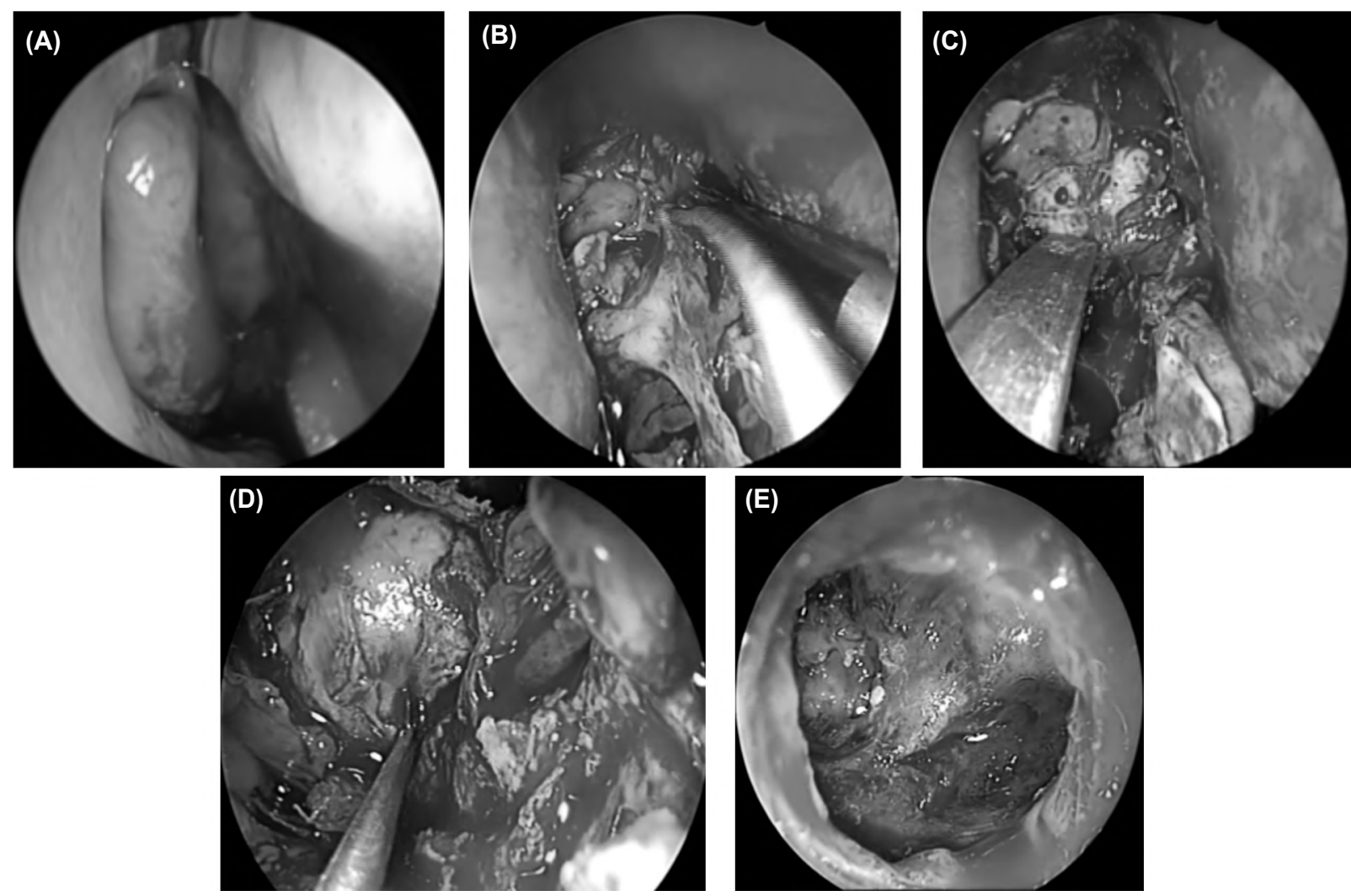

Fig. (2): Intraoperative endoscopic pictures showing: (A): Nasal phase with lateralizing the middle turbinate to explore the sphenoethmoidal recess for the sphenoid ostium. (B): Anterior sphenoidotomy by removing the keel. (C): Opening the sellar floor with a chisel after removing all the sphenoidal septi. (D): Opening the dura with sickle knife. (E): Endoscopic view inside the tumor cavity showing decent of the arachnoid at the end of tumor removal.

Resection of the tumor is then started under close endoscopic visualization using the Binostril bimanual technique. In large pituitary adenomas the normal gland usually could not be identified because of compression by the tumor, but in case of micradenomas, we usually try to identify the normal gland and preserve it.

Dissection of the tumor started with lower part at first then proceed to the posterior part, then using cottonoid patty we push the gland up and dissect both sides of the tumor. This sequence of dissection is very important to avoid early descent of the arachnoid and CSF leak. At the end of tumor removal hemostasis is ensured by using gel foam,
The 3 rd phase is the sellar phase, which starts with opening the sellar floor by using drill or small chisel and hammer Fig. (2C) then expanding the opening of sellar floor from cavernous sinus on one side to the other and from tuberculum recess above to the clivus below. Opening the dura is then made using sickle sharp arachnoid knife in cruciate fashion starting from up down and from cavernous sinus to midline to avoid accidental injury to vascular structure (Fig 2D). Sometimes we used bipolar coagulation to control bleeding from dural intercavernous siuses.

usually do not routinely close the sellar floo unless there is perioperative CSF leak, in which we do formal closure using fat graft to pack the sella Fig. (4), then pieces of bone harvested from nasal septum are anchored to sellar floor between the dura and bony edge will maintain the fat graft in place Fig. (5). Although not necessary we used post-operative nasal pack for 24 hours after surgery for all patients to minimize post-operative nasal bleeding from mucosal dissection.

Perioperative corticosteroid is given to all patients, until they leave the hospital and consult their endocrinologist. Pre-operative antibiotics were given to all patients and continued until they 
leave the hospital. All patients had been sent to intermediate care unit after surgery for close observation for 24-48 hours and then transferred to the ward. Patients were monitored for hypernatremia and polyurea for early detection of DI. Patients were given 50mg of hydrocortisone BID as long as they were in hospital due to difficulty in accurate monitoring of serum cortisol level. CSF leak was closely monitored after pack removal.

\section{Post-operative evaluation:}

Post-operative MRI scan, visual assessment, and endocrinological tests were done and reviewed for all patients MRI scan were routinely done at 2 months, then repeated at 1 year and then annually. Scans were repeated earlier, in cases of inadequate outcome to plan for further step in management.

Gross total removal is considered when the early post-operative scan is free from visualized tumor. Incomplete resection is considered when residual part of the tumor is still there in the early follow-up scans. Visual improvement is indicated by visual field assessment using perimetery. For the functioning pituitary tumor, normalization of hormonal levels post-operatively were considered cure from the disease. This had been estimated individually according to the type of hormone secretion; in GH secreting adenomas GH level below $2.5 \mathrm{ng} / \mathrm{ml}$ and IGF1 as adjusted for sex and age were considered criteria for cure. In Cushing's disease, early post-operative results of morning cortisol below $5 \mathrm{ng} / \mathrm{dl}$ were considered cure. Patients with prolactinomas level below $25 \mathrm{ng} / \mathrm{dl}$ and clinical improvement of pre-operative symptoms were considered cure. These lab tests may be repeated according to clinical situation of the patients in the follow-up period.

All patients had been sent to endocrinologist postoperatively for better assessment and replacement therapy when needed.

\section{Results}

We operated on 35 patients with pituitary adenomas, $19(54.3 \%)$ were females and $16(45.7 \%)$ were males, with their age ranged from 22 to 71 years (mean 36.4 years). The most common presenting symptoms were endocrinological disturbance in $15(42.8 \%)$ patients, and deterioration in vision in $15(42.8 \%)$ patients, other symptoms as headache was apparent in $4(11.4 \%)$ patients and panhypopituitarism in $3(8.6 \%)$ patients. 6 patients $(17.2 \%)$ in this study had a recurrent tumor after previous transsphenoidal surgery, of them 2 patients were GH secretory and 4 patients were non functioning adenomas.
The overall number of patients with macroadenomas in this study is 29 patients $(82.8 \%)$, while 6 patients had microadenomas (17.2\%). Among the 20 patients $(57.2 \%)$ with nonfunctioning adenomas in this study, 9 tumors $(45 \%)$ had suprasellar extension and 11 tumors $(55 \%)$ had parasellar extension mainly towards the cavernous sinus (Table 1).

Functioning adenomas in this study included 15 patients $(42.8 \%), 8$ of them were GH secretory adenomas, 3 crushing's disease, and 4 prolactin secretory adenomas. 6 out of the $8 \mathrm{GH}$ secretory tumors were macroadenomas (5 with suprasellar extension and 1 with parasellar cavernous sinus extension), and the other 2 were microadenomas. The 4 prolactin secreting adenomas included 3 with suprasellar extension, and 1 microadenoma. All the 3 ACTH secreting adenomas were microadenomas in this study Fig. (3).

\section{Degree of tumor resection:}

Gross total resection had been achieved in 23 patients $(65.7 \%)$ as judged intraoperatively and confirmed by early post-operative MRI scan. These patients included $6(17.1 \%)$ with intrasellar microadenomas, and 17 (48.6\%) macroadenomas with supr-asellar extension only.

12 patients (34.3\%) achieved incomplete resection with residual tumor in postoperative followup MRI scan. All the 12 patients had parasellar extension to the cavernous sinus (Table 2).

\section{Visual outcome:}

Among 15 patients with visual deficits included in this study, 13 patients $(86.6 \%)$ showed improvement in their vision, $9(60 \%)$ of them had complete normalization of their pre-operative deficits, 4 patients $(26.6 \%)$ had partial recovery only, and 2 patients $(13.3 \%)$ showed no improvement. No postoperative vision worsening was observed in this study (Table 3).

\section{Endocrinological outcome:}

GH secreting tumors in this study included 8 patients, 6 of them (75\%) showed endocrinological cure post-operatively as indicated by normalization of GH and IGF1 levels, only 2 patients (25\%) did not fulfill criteria of cure.

Prolactin secreting adenomas were operated in our study only in case of tumor growth in spite of medical treatment, rapid deterioration of visual symptoms, and intolerance to medical treatment. Out of our 4 patients with prolactin secreting adenomas, $3(75 \%)$ showed normalization of pro- 
lactin level after surgery, and one patient showed persistent abnormal prolactin level.

Three patients in this study had confirmed Cushing's disease clinically and after endocrinological evaluation. Although the 3 patients had microadenomas beside the normal gland and gross total resection in postoperative MRI scan, only 2 (66.7\%) patients had endocrinological cure, and one $(33.3 \%)$ patient remained with high ACTH level and had no clinical improvement (Table 4).

\section{Surgical complications:}

Surgical complications encountered in this study are shown in (Table 5).

Most of patients in our study were discharged from hospital after the $3 \mathrm{rd}$ day post-operative, some patients with CSF leak and DI were kept in the department for a week to ensure that they are free from DI or CSF leak before discharge. Generally, hospital stay ranged from 3 to 7 days.

Follow-up period ranged from 4 months to 36 months mean (18.4 months). During the period of follow-up we observed 6 cases $(17.2 \%)$ of recurrence of symptoms with regrowth of the tumor due to incomplete removal and failure of giving proper postoperative adjuvant therapy. 29 patients $(82.8 \%)$ showed no local recurrence during the whole follow-up period.

Table (1): Patients demographic data.

\begin{tabular}{lc}
\hline Description & No. of patients \\
\hline Total No. & 35 \\
Gender: & $16(45.7 \%)$ \\
$\quad$ Male & $19(54.3 \%)$ \\
Female & \\
Most common pres & \\
enting symptom: & \\
Visual deficit & $15(42.8 \%)$ \\
Headache & $4(11.4 \%)$ \\
Endocrinological disturbance & $15(42.8 \%)$ \\
Panhypopituitarism & $3(8.6 \%)$ \\
Size: & \\
$\quad$ Microadenomas & $6(17.2 \%)$ \\
Macroadenomas & $29(82.8 \%)$ \\
Function: & \\
- Non functioning: & \\
Suprasellar extension only & 20 \\
Parasellar extension & $9 / 20(45 \%)$ \\
- Functioning: & $11 / 20(55 \%)$ \\
GH secretory & \\
Prolactin secretory & $8 / 15(53.3 \%)$ \\
ACTH secretory & $4 / 15(26.6 \%)$ \\
\hline & $3 / 15(20 \%)$ \\
\hline
\end{tabular}

Table (2): Degree of resection.

\begin{tabular}{lll}
\hline $\begin{array}{l}\text { Degree of } \\
\text { resection }\end{array}$ & No. of patients \\
\hline $\begin{array}{l}\text { Gross total } \\
\text { resection }\end{array}$ & $23(65.7 \%)$ & $\begin{array}{l}6(17.2 \%) \text { microadenomas } \\
17(48.6 \%)\end{array}$ \\
& \multicolumn{1}{c}{$\begin{array}{c}\text { extension only } \\
\text { Incomplete }\end{array}$} & $\begin{array}{l}12(34.3 \%) \\
\text { resection }\end{array}$ \\
\hline
\end{tabular}

Table (3): Visual outcome.

\begin{tabular}{lll}
\hline $\begin{array}{l}\text { Visual } \\
\text { improvement }\end{array}$ & No. of patients & \\
\hline Improved & $13(86.6 \%)$ & $\begin{array}{l}9(60 \%) \text { complete } \\
4(26.6 \%) \text { partial }\end{array}$ \\
Not improved & $2(13.4 \%)$ & \\
\hline
\end{tabular}

Table (4): Endocrinological outcome.

\begin{tabular}{lcll}
\hline Type of tumor & No. & Cure & Non cure \\
\hline GH secretory & 8 & $6 / 8(75 \%)$ & $2 / 8(25 \%)$ \\
Prolactin secretory & 4 & $3 / 4(75 \%)$ & $1 / 4(25 \%)$ \\
ACTH secretory & 3 & $2 / 3(66.7 \%)$ & $1 / 3(33.3 \%)$ \\
\hline Total & 15 & $11 / 15(73.3 \%)$ & $4 / 15(26.7 \%)$ \\
\hline
\end{tabular}

Table (5): Surgical complication.

\begin{tabular}{|c|c|c|}
\hline Type of complication & \multicolumn{2}{|c|}{ Number of patients $(\%)$} \\
\hline Intraoperative CSF leak & & $6(17.2 \%)$ \\
\hline Postoperative CSF leak & & $1(2.9 \%)$ \\
\hline \multicolumn{3}{|l|}{$D I:$} \\
\hline Temporary & $10(28.6 \%)$ & $8(22.9 \%)$ \\
\hline Persistent & & $2(5.7 \%)$ \\
\hline Sinus mucocel and nasal discharge & & $3(8.6 \%)$ \\
\hline $\begin{array}{l}\text { Transient disturbance in hormonal } \\
\text { level (cortisol) }\end{array}$ & & $2(5.7 \%)$ \\
\hline Worsening of vision & & $0(0 \%)$ \\
\hline Optic or vascular injuries & & $0(0 \%)$ \\
\hline Death & & $0(0 \%)$ \\
\hline
\end{tabular}

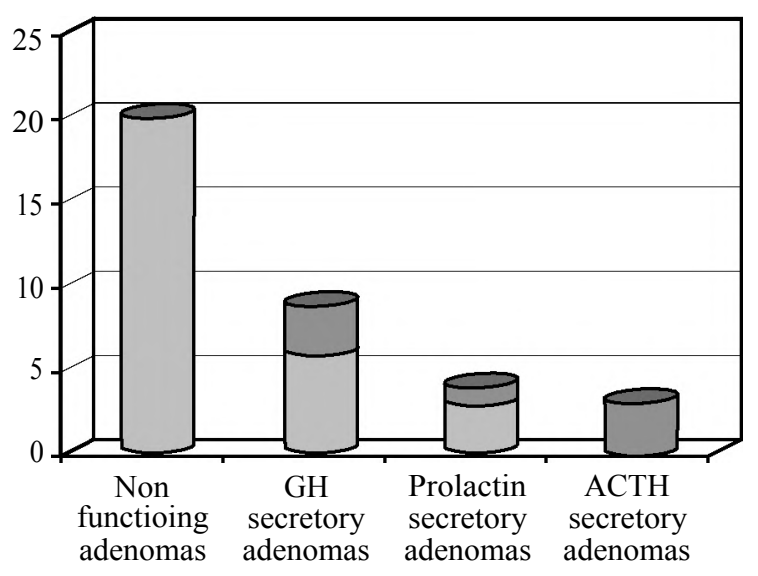

Microadenomas $\square$ Macroadenoma

Fig. (3): Size of adenoma among different types of hormone secreting adenomas. 

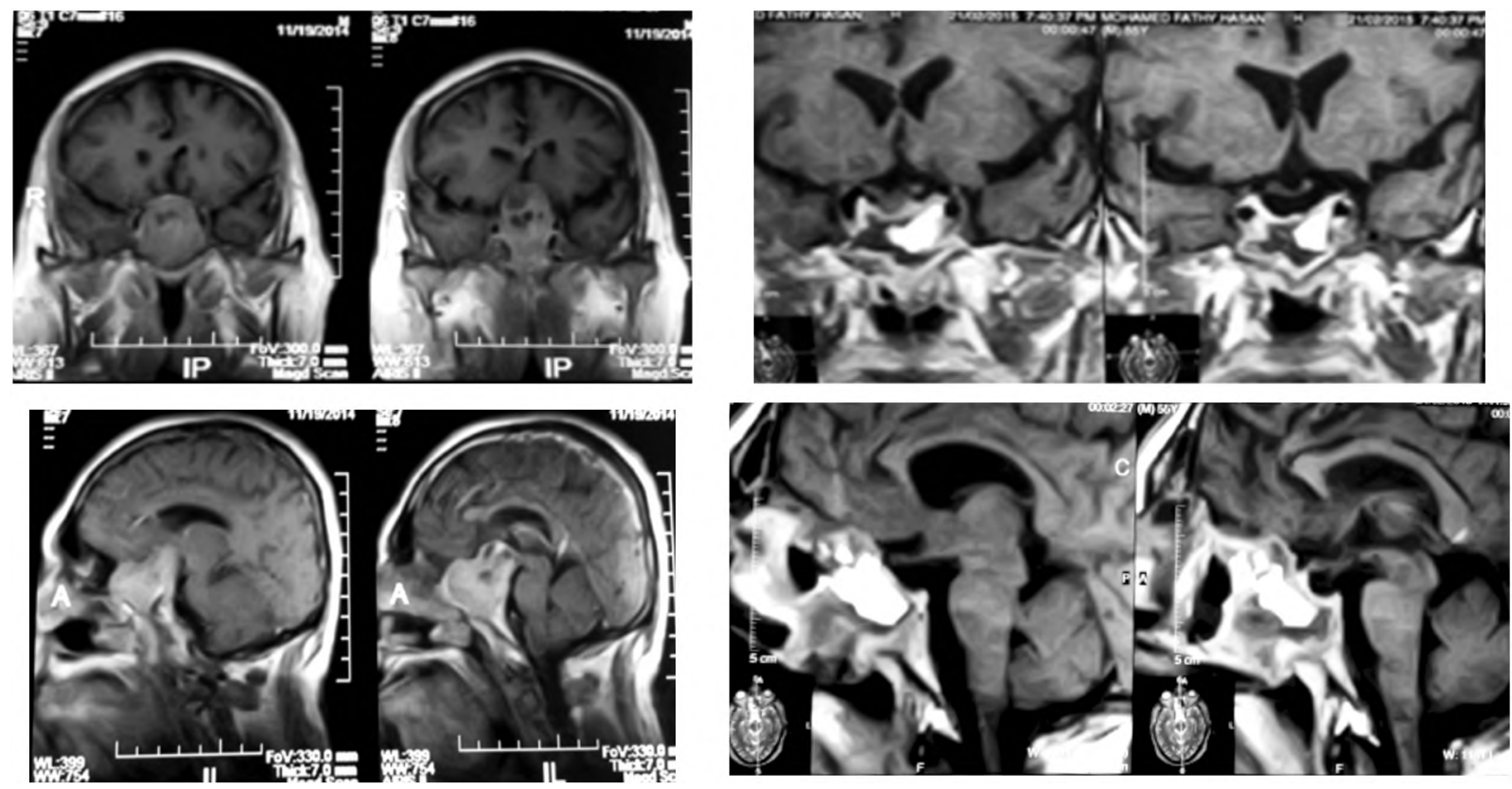

Fig. (4): MRI pictures of 48 years old male presented with diminution of vision and Acromegally, with large suprasellar pituitary tumor (pictures on the left), underwent endoscopic endonasal tumor removal, with total resection of the tumor as appeared in the post operative MRI ( pictures on the RT). Notice the fat graft packing the sella to prevent post operative CSF leak.
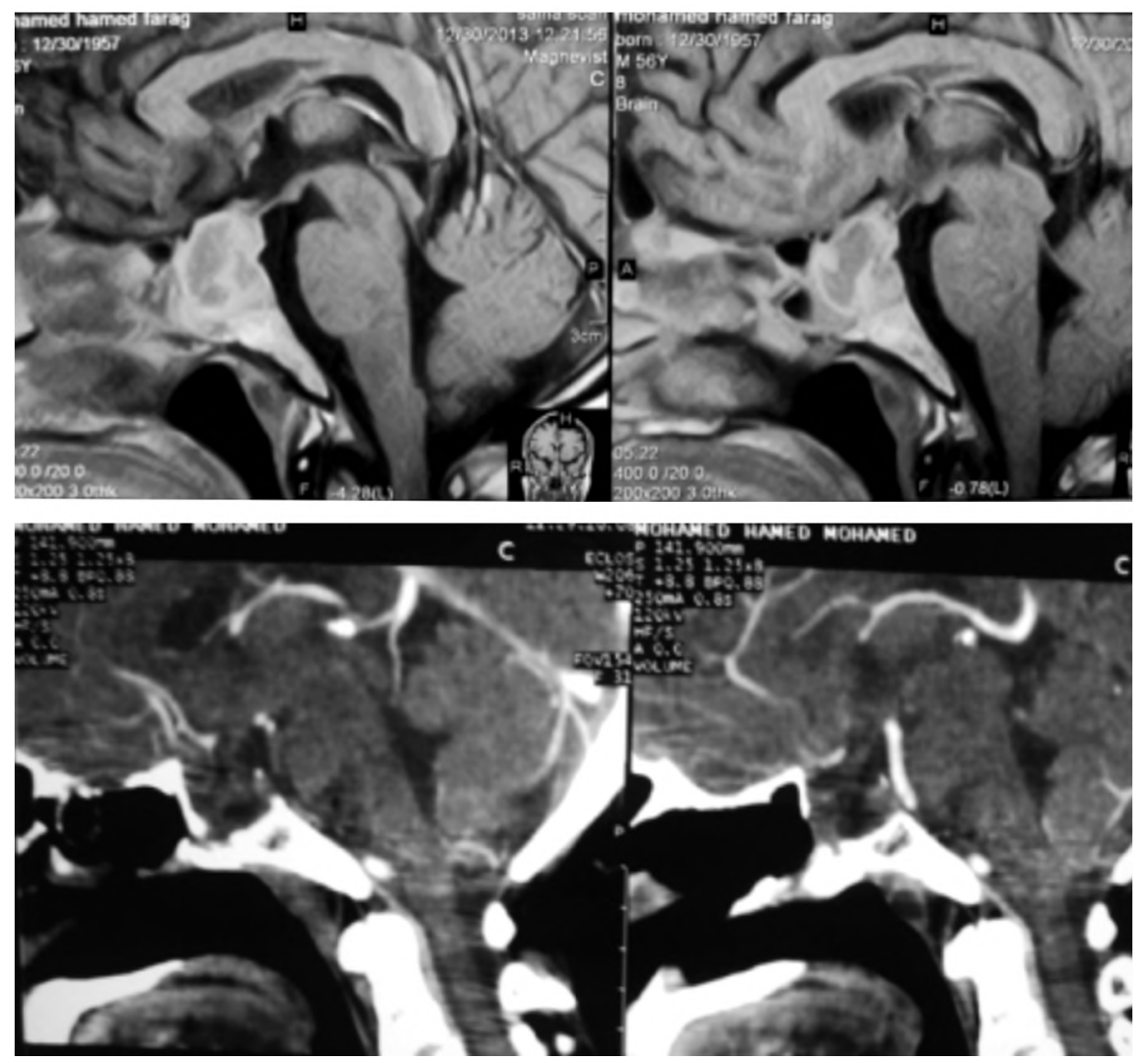

Fig. (5): Pre and post operative sellar images for 65 years old man with acute onset of diminution of vision showing large suprasellar pituitary adenoma with apoplexy that has been removed totally using the pure endoscopic endonasal technique. Notice the reconstruction of the sellar floor with bone harvested from nasal septum in the postoperative image. 


\section{Discussion}

Transsphenoidal surgery for pituitary tumors has been refined since its introduction in 1897. David Giordane introduced his anatomic studies to reach the sella through direct transsphenoidal approach. The surgery then was performed on real patient for the first time by schloffer in 1907 [3] .

The sublabial transsphenoidal approach then had been introduced and popularized by Harvey Cushing from 1912-1925. The first report to use endoscope in pituitary surgery was by Gerard Guiot; a french neurosurgeon, in 1963, he abandoned the technique because of lack of illumination and visualization while using the endoscope, but he should be accredited for being the ${ }^{1 \text { st }}$ neurosurgeon to use endoscope in pituitary surgery [4]

Then, with technological advancement of using the cylindrical rod lens fiberoptic bundles, computer chips, and video cameras, the real evolution of pure endoscopic endonasal started in early 1990s. the popularity of endoscopic endonasal technique started with the collaborative work between ENT endoscopic sinus surgeon and neurosurgeon interested in this technique [4].

In 1997, Jho and Carrau reported a series of 50 patients who underwent endoscopic endonasal surgery for pituitary tumors with encouraging results [5] . This was followed by cappabianca et al, who reported outcome of 100 patients with same technique [6]. Other reports since then were published with more numbers of patients with better results compared to traditional microscopic surgery [7].

The technique has been disseminated worldwide until it became the main surgical approach for pituitary tumor resection in many neurosurgical centers.

The panoramic view offered by the endoscope inside the surgical area, the close up of the anatomy to the surgeon eye, together with the exploration of different working angles, are some advantage offered by the use of endoscope in pituitary surgery. The pure endoscopic endonasal technique added to this, less trauma to the nasal cavity without the need for any sublabial dissection [8] .

The main obstacle we faced in our early cases with this technique was the familiarity with the endoscopic anatomy, this was overcame by a lot of dissection that has been made in the anatomy lab and during pituitary courses. We found this very important before starting this technique.
The 2 nd main obstacle we faced was how to use the instrument together with the endoscope through the small opening of the nose. To overcome this we passed through a learning curve that was frustrated in the beginning and then after our 1 st 10 cases we became familiar with it. Also, we found the bimanual Binostril technique very helpful in the progress of our learning curve because of the similarity to the dissection done under the microscope.

The 2 dimensional vision offered by the endoscope at the beginning was frustrating to us. Touching 3 points at different levels at the beginning of surgery was very helpful until our eyes make the stereoscopic vision needed to complete the surgery.

The frequent need for lens cleaning during endoscopic surgery is usually done by designed lens cleaning devise called clear vision made by Storz [1]. However, we found repeated wash with warm saline and touching the tip of the lens with gauze soaked with cetavlon solution very helpful to overcome this problem.

Using the navigation system usually makes the surgery very safe and accurate [9], however in our cases we relied mainly on revising the detailed anatomy of the sphenoid cavity and sella during every step of dissection. We did not encounter any vascular injury, optic nerve injury or accidental perforation of the anterior cranial base.

Although some authors advocated performing this surgery without the assistant of the ENT surgeon [10] we found the team work between the ENT surgeon and the neurosurgeon very helpful in performing successful surgery due to their much more experience in dealing with nasal septum and nasal cavity anomalies.

The results of pure endoscopic pituitary surgery for tumor resection, visual improvement, and hormonal cure have been heavily discussed and compared to that obtained by conventional microscopic surgery in the literature [2,11-13]

\section{Extent of tumor resection:}

In our study GTR of the tumor was obtained in 23 patients $(66 \%)$ however, incomplete resection with residual tumor in post-operative scan was obtained in 12 patients (34\%). The GTR group included 6 microadenomas, and 17 macroadenomas with suprasellar extension only.

While the other group included 12 macroadenomas with parasellar extension mainly to the cavernous sinus. 
The rate of endoscopic GTR of pituitary tumor among the literature varies from $62 \%$ to $93 \%$ [14] The main reason for this wide range between studies was mostly due to the learning curve required to master the technique in addition to parasellar extension of the tumor $[\mathbf{1 5 , 1 6 ]}$.

The main reason for incomplete resection in our study was the cavernous sinus invasion by the tumor in addition to firmness of some recurrent tumors. Jain et al., observed that tumor volume of less than 5cc with no parasellar extension are favorable variable for total removal [17].

\section{Extent of surgical exposure:}

In our study we operated on 6 recurrent tumor done by microscopic technique previously. The improved visualization offered by the endoscope helped us in locating the residual part of the tumor hidden to the microscopic view. We observed a suboptimal opening at the sphenoid keel and the sellar floor that was mostly the reason for previous incomplete removal and subsequent recurrence. This limited exposure in previously treated patients with microscopic surgery has been observed by others $[\mathbf{1 8 , 1 9 ]}$

\section{Visual outcome:}

Among 15 patients with visual symptoms in our study, 13 patients (87\%) showed degree of improvement, while only 2 patients $(13 \%)$ showed no improvement. Full visual recovery has been gained in 9 patients $(60 \%)$, while partial recovery occurred in 4 patients (27\%). Comparable results have been shown by Dehdashti et al., 2008, with normalization in $50 \%$ of patients and improvement in $39 \%$ of patients [11]. Similar results have been found by other others [20].

\section{Hormonal control:}

Cure from hormonal disturbance after pituitary surgery is challenging issue in all types of pituitary surgery this is due to the fact that very small residual of functioning tumor can still produce excess hormones. That is why hormonal cure is very difficult to be achieved without complete resection of the tumor $[\mathbf{1 2 , 1 5 ]}$.

In our study although the 3 patients with Cushing's disease had microadenomas with GTR, 2 only cured and one did not cure, most probably due to other small parts inside the gland or at the stalk. This patients has been prepared for subtotal hypophysectomy.

In a large series of Cushing's disease operated endoscopically the authors reported cure from hypercortisolism in $77 \%$ of patients after the first surgery [21]

Among the 8 patients with GH secreting adenoma in our study, 6 patients $(75 \%)$ showed hormonal control, while 2 patients $(25 \%)$ was not cured by surgery alone. One of these 2 patients had parasellar extension and was sent to gamma knife, the other one although had GTR, he continued to have high IGF1 levels that necessitate the patients to start sandostatin treatment. Hormonal control results after endoscopic surgery varied in literature from $65 \%$ to $85 \%$ [14,22].

The 4 patients with prolactin secreting tumor in our study showed cure in 3 patients $(75 \%)$ and non cure in one patient $(25 \%)$ due to parasellar extension and incomplete removal. This patient was then referred for medical treatment again.

Cure rate in endoscopically treated prolactinomas ranged from $64 \%$ to $100 \%$ in the literature $[14,23,24]$.

\section{Complications:}

The most common complication encountered in our study was intraoperative CSF leak in 6 patients $(17 \%)$, most of these cases were at our early experience due to early descent of the arachnoid during dissection of the tumor. These patients were managed by packing the sella with fat graft and closing the floor with a piece of bone harvested from the nasal septum. Only one patient (2.8\%) had post-operative CSF leak that needed another surgery for repair with fascia lata graft and fibrin glu together with fat graft [25]. No reported cases of meningitis. CSF leak has been mentioned in the endoscopic literature to be varied from 1.2$6 \%[26]$

Transient DI has been observed in 8 patients (22\%), with permanent DI in 2 patients in our study. These results may be higher than that observed in the literature which vary from 1-3.5\% in permanent DI and $2.3 \%$ in transient DI $[9,14]$

Minor nasal complications as sinus mucocele and nasal discharge occurred in 3 patients (8\%) in this study, all of them were early cases due to formation of nasal adhesions between the middle turbinate and the lateral nasal wall. To avoid this, returning the middle turbinate to its place is important at the end of the procedure.

Five patients (14\%) had recurrent symptoms after initial improvement due to the partial removal of the tumor during the follow-up period, those 
patients underwent another surgery but is not included in this study.

\section{Limitation of the study:}

This study is limited by a small number of patients that make it mostly of a descriptive nature, and no comparison has been done between this technique and other techniques of pituitary surgery. Another limitation is the short follow-up period, so good evaluation of recurrent tumors cannot be done. However, this study showed our early experience in adopting pure endoscopic endonasal pituitary surgery, the challenges we faced and the problem we solved to start this technique which was not done before in our department.

\section{Conclusion:}

The panoramic view offered by the endoscope has great advantage in bringing the anatomy closer to the surgeon's eye so that we can follow the extrasellar part of the tumor with better visualization. The pure endoscopic endonasal technique, although challenging, it is less traumatic, and associated with good outcome. Long term control data and longer series is still needed for more evaluation of the technique.

\section{Acknowledgment:}

The authors thank all included patients.

\section{Funding:}

This study had no funding from any resource.

\section{Competing interests:}

The authors declare that they have no conflict of interest.

\section{Ethical approval:}

This research accepted by Research Ethics Committee (REC) of Faculty of Medicine, Benha University (Chairman: Prof/Ibrahim El-Gendy).

All procedures performed in studies involving human participants were in accordance with the ethical standards of the institutional and/or National Research Committee and with the 1964 Helsinki declaration and its later amendments or comparable ethical standards. A written informed consent was obtained from each patient after explaining all steps of this study.

\section{Authors' contributions:}

Mohammed El-Tantawy, Ahmed Arab, and Mohammed Gamil performed the clinical part of the study, analyzed the data and wrote with meticulous revision of the paper.

\section{References}

1- CAPPABIANCA P., CAVALLO L.M., SOLARI D., STAGNO V., ESPOSITO F. and De ANGELIS M.: Endoscopic endonasal surgery for pituitary adenomas. World Neurosurg. Dec., 82 (6 Suppl): S3-11, 2014.

2- ESQUENAZI Y., ESSAYED W.I., SINGH H., MAUER E., AHMED M., CHRISTOS P.J. and SCHWARTZ T.H.: Endoscopic Endonasal Versus Microscopic Transsphenoidal Surgery for Recurrent and/or Residual Pituitary Adenomas. World Neurosurg. May, 101: 186-95, 2017.

3- LIU J.K., DAS K., WEISS M.H., LAWS E.R. Jr. and COULDWELL W.T.: The history and evolution of transsphenoidal surgery. J. Neurosurg., 95: 1097-103, 2001.

4- DOGLIETTO F., PREVEDELLO D.M., JANE J.A. Jr., HAN J. and LAWS E.R. Jr.: A brief history of endoscopic transsphenoidal surgery-from Philipp Bozzini to the First World Congress of Endoscopic Skull Base Surgery. Neurosurg. Focus, 19 (6): E3, 2005

5- JHO H. and CARRAU R.: Endoscopic endonasal transsphenoidal surgery: Experience with fifty patients. J. Neurosurg., 87: 44-51, 1997.

6- CAPPABIANCA P., ALFIERI A. and De DIVITIIS E. Endoscopic endonasal transsphenoidal approach to the sella: Towards functional endoscopic pituitary surgery (FEPS). Minim Invasive Neurosurg, 41: 66-73, 1998.

7- KABIL M.S., EBY J.B. and SHAHINIAN H.K.: Fully endoscopic endonasal versus transseptal transsphenoidal pituitary surgery. Minim Invasive Neurosurg., 48: 348 54, 2005.

8- SHEN C.C., WANG Y.C., HUA W.S., CHANG C.S. and SUN M.H.: Endoscopic endonasal transsphenoidal surgery for pituitary tumors. Chin. Med. J. Taipei., 63: 301-10, 2000.

9- CAPPABIANCA P., CAVALLO L.M., COLAO A. and De DIVITIIS E.: Surgical complications associated with the endoscopic endonasal transsphenoidal approach for pituitary adenomas. J. Neurosurg., 97: 293-8, 2006.

10- JHO H.D.: Endoscopic transsphenoidal surgery. J. Neurooncol., 54: 187-95, 2001.

11-DEHDASHTI A.R., GANNA A., KARABATSOU K. and GENTILI F.: Pure endoscopic endonasal approach for pituitary adenomas: Early surgical results in 200 patients and comparison with previous microsurgical series. Neurosurgery. May, 62 (5): 1006-15; Discussion 1015-7, 2008 .

12-TABAEE A., ANAND V.K., BARRÓN Y., HILTZIK D.H., BROWN S.M., KACKER A., MAZUMDAR M. and SCHWARTZ T.H.: Predictors of short-term outcomes following endoscopic pituitary surgery. Clin. Neurol. Neurosurg., 2: 119-22, 2008.

13- FRANK G., PASQUINI E., FARNETI G., MAZZATENTA D., SCIARRETTA V., GRASSO V. and FAUSTINI FUSTINI M.: The endoscopic versus the traditional approach in pituitary surgery. Neuroendocrinology, 83: 2408, 2006.

14- GONDIM J.A., SCHOPS M., De ALMEIDA J.P., De ALBUQUERQUE L.A., GOMES E., FERRAZ T. and BARROSO F.A.: Endoscopic endonasal transsphenoidal 
surgery: Surgical results of 228 pituitary adenomas treated in a pituitary center. Pituitary, 13 (1): 68-77, 2010.

15- DO H., KSHETTRY V.R., SIU A., BELINSKY I., FARRELL C.J., NYQUIST G., ROSEN M. and EVANS J.J.: Extent of Resection, Visual, and Endocrinologic Outcomes for Endoscopic mEndonasal Surgery for Recurrent Pituitary Adenomas. World Neurosurg. Jun., 102: 35-41, 2017.

16- JURASCHKA K., KHAN O.H., GODOY B.L., MONSALVES E., KILIAN A., KRISCHEK B., GHARE A., VESCAN A., GENTILI F. and ZADEH G.: Endoscopic endonasal transsphenoidal approach to large and giant pituitary adenomas: Institutional experience and predictors of extent of resection. J. Neurosurg., Jul., 121 (1): 75-83, 2014.

17- JAIN A.K., GUPTA A.K., PATHAK A., BHANSALI A. and BAPURAJ Jr.: Endonasal transsphenoidal pituitary surgery: Is tumor volume a key factor in determining outcome? Am. J. Otolaryngol., 29 (1): 48-50, 2008.

18- MATTOZO C.A., DUSICK Jr., ESPOSITO F., MORA H., COHAN P., MALKASIAN D. and KELLY DF: Suboptimal sphenoid and sellar exposure: A consistent finding in patients treated with repeat transsphenoidal surgery for residual endocrine-inactive macroadenomas. Neurosurgery, 58: 857-65, 2006.

19- SANMILLÁN J.L., TORRES-DIAZ A., SANCHEZFERNÁNDEZ J.J., LAU R., CILLER C., PUYALTO P. and GABARRÓS A.: Radiologic Predictors for Extent of Resection in Pituitary Adenoma Surgery. A Single-Center Study. World Neurosurg. Dec., 108: 436-46, 2017.

20- FREDES F., UNDURRAGA G., ROJAS P., CONSTANZO F., LAZCANO C., PINTO J. and SCHMIDT T.: Visual Outcomes after Endoscopic Pituitary Surgery in Patients Presenting with Pre-operative Visual Deficits. J. Neurol. Surg. B. Skull. Base. Dec., 78 (6): 461-5, 2017.
21- NETEA-MAIER R.T., VAN LINDERT E.J., DEN HEIJER M., VAN DER EERDEN A., PIETERS G.F., SWEEP C.G., GROTENHUIS J.A. and HERMUS A.R.: Transsphenoidal pituitary surgery via the endoscopic technique: Results in 35 consecutive patients with Cushing's disease. Eur. J. Endocrinol., 154: 675-84, 2006.

22- ALMEIDA J.P., RUIZ-TREVIÑO A.S., LIANG B., OMAY S.B., SHETTY S.R., CHEN Y.N., ANAND V.K., GROVER K., CHRISTOS P. and SCHWARTZ T.H.: Reoperation for growth hormone secreting pituitary adenomas: Report on an endonasal endoscopic series with a systematic review and meta-analysis of the literature. J. Neurosurg. Sep., 1: 1-13, 2017.

23- TABAEE A., ANAND V.K., BARRÓN Y., HILTZIK D.H., BROWN S.M., KACKER A., MAZUMDAR M. and SCHWARTZ T.H.: Endoscopic pituitary surgery: A systematic review and meta-analysis. J. Neurosurg. Sep., 111 (3): 545-54, 2009.

24- CHO D.Y. and LIAU W.R.: Comparison of endonasal endoscopic surgery and sublabial microsurgery for prolactinomas. Surg., Neurol., 58: 371-6, 2002.

25- STRICKLAND B.A., LUCAS J., HARRIS B., KULUBYA E., BAKHSHESHIAN J., LIU C., WROBEL B., CARMICHAEL J.D., WEISS M. and ZADA G.: Identification and repair of intraoperative cerebrospinal fluid leaks in endonasal transsphenoidal pituitary surgery: Surgical experience in a series of 1002 patients. J. Neurosurg. Sep., 29: 1-5, 2017.

26- ZHOU Q., YANG Z., WANG X., WANG Z., ZHAO C., ZHANG S., LI P., LI S. and LIU P.: Risk Factors and Management of Intraoperative Cerebrospinal Fluid Leaks in Endoscopic Treatment of Pituitary Adenoma: Analysis of 492 Patients. World Neurosurg. May, 101: 390-5, 2017. 


\section{الجراحة التامة بالمنظار من خلال الأنف لعلاج أورام الغلدة النخامية.

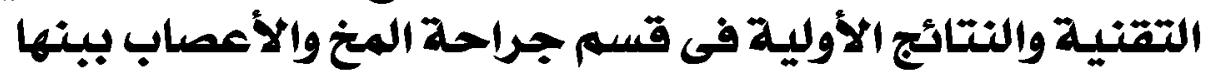

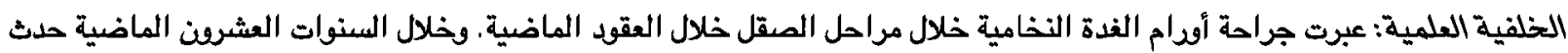

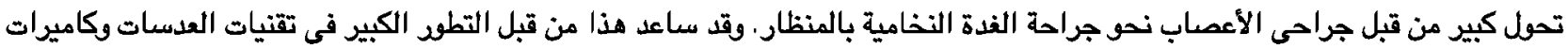

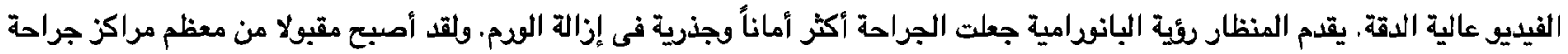

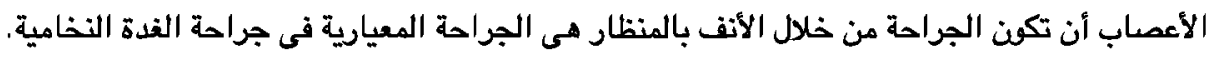

الأهدف: فى هذه الدراسدة نبلغ نتائجنا المبكرة والتعديات التى واجهناها والمشاكل التى قمنا بحلها فى تطبيق تقنية جراحة المنظار لأورام

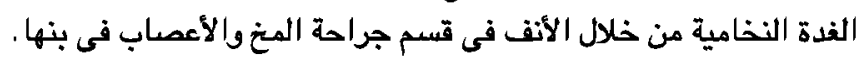

تصميم الدراسة: هو دراسية إكلينيكية إسترجاعية على هب مريضاً بأقدام الغدة النخامية. تم علاج جميع المرضى جراحياً بأستخدام تقنية

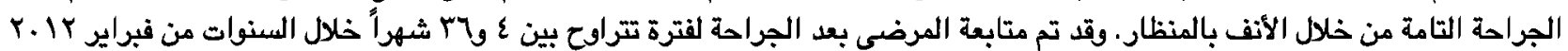
إلى مارس 10 . إس

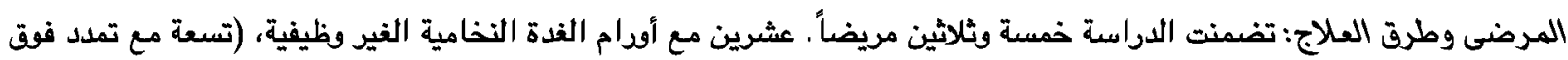

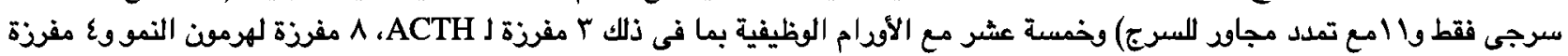

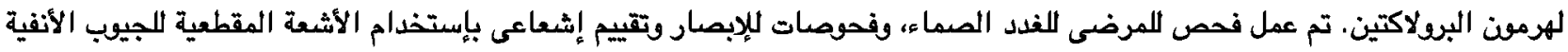
والتصوير بالرنين المغناطيسى اللغدة النخامية، تم مقارنة ما قبل وبعد العمليات الجراحية وكذلك مستويات هرمونات الفدة الفئ النخامية وتقييم درجة

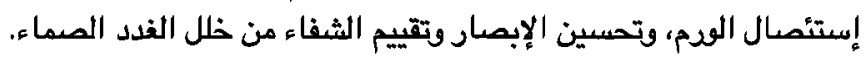

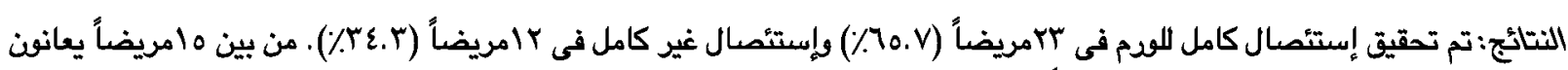

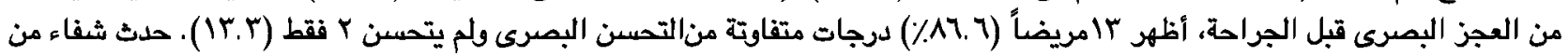

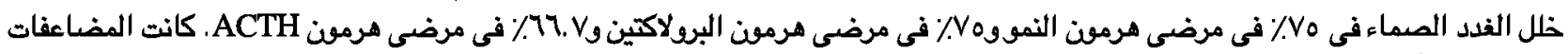

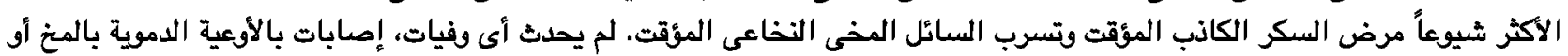
انتكاسات بالإبصار.

الأستتاج: تقنية العلاج الجراحى لأورام الغدة النخامية بالمنظار من خلال الأنف هى تقنية ممتازة فهى أقل صدمة للأنسجة، وأظهرت نتائج 